\title{
Megacystis Microcolon Intestinal Hypoperistalsis Syndrome: An Overview
}

\section{Mostafa Kotb ${ }^{1 *}$, Marwa Beyaly ${ }^{2}$}

${ }^{1}$ Assistant Lecturer of Pediatric Surgery, Alexandria Faculty of Medicine, Egypt.

2 Epidemiologist and Human Genetics Researcher, Alexandria Medical Research Institute, Egypt.

*Corresponding Author : Mostafa Kotb, Department of Pediatric Surgery, Alexandria Faculty of Medicine, Alexandria, Egypt. Email: mostafa.rashad@alexmed.edu.eg

Received date: February 10, 2019;Accepted date : March 15, 2019; Published date: March 20, 2019.

Citation : Mostafa Kotb, Marwa Beyaly. Megacystis Microcolon intestinal hypoperistalsis syndrome: An overview J. Gastroenterology Pancreatology and Hepatobilary Disorders. 3(1). Doi: 10.31579/2641-5194/008

Copyright : (c) 2019 Mostafa Kotb. This is an open-access article distributed under the terms of The Creative Commons Attribution License, which permits unrestricted use, distribution, and reproduction in any medium, provided the original author and source are credited.

\section{Abstract \\ Megacystis Microcolon Intestinal Hypoperistalsis Syndrome (MMIHS) is a rare congenital anomaly that is considered the most severe form of functional obstruction of the gastrointestinal tract. This devastating condition is composed of non-obstructed urinary bladder, microcolon with decreased or absent intestinal peristalsis. This study was designed to describe the incidence and outcome of MMIHS.}

Key word: megacystis

\section{Introduction}

Megacystis microcolon intestinal hypoperistalsis syndrome (MMIHS) is a rare congenital anomaly, which is characterized by, as its name implies, abdominal distension caused by a largely distended nonobstructed urinary bladder, microcolon with decreased or absent intestinal peristalsis (1). Owing to its high mortality rate, it is considered the most severe form of neonatal intestinal obstruction ${ }^{2}$. Since the description of the first case of MMIHS, many case reports had been published and various theories have been postulated. Despitethis, the etiology of this disease remains unclear. This condition showed female predominance, with history of consanguinity in many cases suggesting an autosomal recessive pattern of inheritance (2).

The treatment of MMIHS is mainly supportive. Prokinetic drugs, gastrointestinal hormones failed to improve peristalsis. While surgical options can help in nutrition and for relief of the bowel obstruction, intestinal function does not usually improve and functional obstruction frequently recurs. Therefore, intestinal and multivisceral transplantation appears to be the only viable therapeutic option for children with severe gastrointestinal dysmotility (3). The aim of this review was to determine the epidemiology and outcomes of MMIHS cases reported to date.

\section{Methods}

A PubMed search was performed for the key words "megacystis microcolon intestinal hypoperistalsis" with no restriction on publication language. All studies reporting patients with the diagnosis of MMIHS in the period from 1976 to date were included. Detailed information with emphasis on epidemiology, diagnosis, surgical findings and outcome were recorded and critically analyzed.

\section{Results}

To our best knowledge, a total number of 246 patients were identified in the literature during the period from 1976 to 2018 (4). Prenatally, diagnosis was confirmed in one quarter of the cases, where $87 \%$ showed megacystis. In nine cases only, parents accepted the option of termination of pregnancy after prenatal diagnosis of MMIHS and genetic counseling. Gender was mentioned in 199 cases. Of these, 137 patients (approximately 69\%) were females, whilst $62(31 \%)$ were males. The female-to-male ratio was $2.2: 1$. In about half of the patients (129 patients), one or more surgical interventions were reported. As its name implies, megacystis and microcolon were the most frequent findings at autopsy or surgery. Moreover, malrotation was reported in 95 patients, dilated proximal small bowel in 36, short bowel in 41 , and segmental stenosis of small bowel in

7. A range of interventions was reported including gastrostomy, jejunostomy, ileostomy, cecostomy, segmental resection of jejunum and ileum, adhesiolysis, rectal biopsy and internal sphincter myectomy. Vesicostomy was reported in 47 patients. Outcome was reported in 236 patients. Out of those, 185 patients $(78.4 \%)$ died and 51 patients $(21.6 \%)$ were alive at the time of publication (Table 1). The most common cause of death was overwhelming sepsis followed by multiple organ failure and malnutrition. The majority of the survivors were maintained on TPN, while only 12 patients underwent multivisceral transplantations. According to the obtained data, the majority of the survivors were independent of parenteral nutrition, yet, bladder dysfunction persisted and clean intermittent catheterization (CIC) has been reported.

\begin{tabular}{|l|l|l|l|}
\hline \multicolumn{1}{|c|}{ Gender } & & \multicolumn{1}{c|}{ Findings } & \\
\hline Females & $137(69 \%)$ & Megacystis & $246(100 \%)$ \\
\hline Males & $62(31 \%)$ & Malrotation & $95(39 \%)$ \\
\hline Not mentioned & 47 & Proximal dilatation & $36(15 \%)$ \\
\hline & & Short bowel & $41(17 \%)$ \\
\hline Antenatal & & Segmental Stenosis & $7(3 \%)$ \\
\hline Confirmed diagnosis & $63(25 \%)$ & & \\
\hline Megacystis & $212(87 \%)$ & Outcome & $185(78 \%)$ \\
\hline GI anomalies & $56(23 \%)$ & Died & $51(22 \%)$ \\
\hline & & Survived & 10 \\
\hline
\end{tabular}

Table (1): Main features of the 246 MMIHS cases reported in literature Discussion

Since first described in 1976 by Berdon on five girls, 2 of whom aresisters (5), few hundred cases of MMIHS have been reported and contributed to a better understanding of this devastating disease. 
As long as there is neither definitive medical nor surgical treatment have proved to improve the intestinal and bladder dysfunction, the majority of MMIHS patients are therefore dependent on TPN to prevent malnutrition, beside the known complications such as sepsis and renal failure (6).

\section{Epidemiology}

MMHIS is more common in females, with female to male ratio of 2.2:1. Many authors claim that under diagnosis in males is due to the more severe form in males resulting in intrauterine deaths (7), whilst others state that MMIHS can be diagnosed as prune belly syndrome (PBS) instead, leading to a bias in female to male ratio (8). Overlap of MMIHS and PBS have occurred $(9,10)$ although most cases present assporadic ones, MMIHS can occur in a familial fashion. In a study, familial MMIHS was evident in a total of 47 occasions, with 19 families had a pair of affected siblings, and a family had three childrenwith MMIHS (11). It had been suggested that mutation in actin gamma2 (ACTG2) on chromosome 2p13 and loss of leomodin genes, both areresponsible for encoding of one of the six actin myoforms present in the smooth muscles of the urinary and gastrointestinal systems, resulting in their hypoperistalsis $(12,13)$.

\section{Diagnosis}

With improvement in antenatal care, MMHIS can be diagnosed prenataly. Up to $25 \%$ of cases were achieved via prenatal diagnosis. Enlarged bladder (megacystis) was the main finding in $87 \%$ of cases, whilst gastrointestinal anomalies were noted in $23 \%$ only (13). While megacystis is more common in male fetuses, it is usually associated with oligohydramnios and caused by mechanical lower urinary tract obstruction (LUTO). Therefore, MMIHS should not be excluded in male fetuses with megacystis, especially if there is no oligohydramnios. On the other hand, it is strongly suspected in female fetuses with accompanying polyhydramnios because LUTO is rare in females and oligohydramnios is an invariable finding (14). Moreover, amniotic fluid analysis for enzymatic changes, in addition to magnetic resonance imaging, has increased the accuracy of prenatal diagnosis ofMMIHS (15). Therefore, parenteral counselling to ensure that they areaware of the pathology, prognosis, therapeutical options and care of MMIHS should be done in order to make a substantiated decision on the sequel of the pregnancy. Nine couples decided to terminate pregnancy due to prenatal diagnosis of MMIHS in the current literature.

\section{Surgical findings}

Management varied considerably among most publications and exact surgical procedures were reported inconsistently. Since the most frequent findings were megacystis (Figure 1), functional obstruction, and malrotation, therefore, all of the operations were performed mainly to decompress the intestinal and urinary systems. Surgeons frequently chose to perform diverting ileostomy to benefit from early oral feeding to avoid long term TPN, and biopsy to exclude Hirschsprung's disease and other related motility disorders (16). Vesicostomy was reported in less than a fifth of cases only, after considering insertion of Foley catheter for initial decompression. While some authors consider vesicostomy only if catheter was not tolerated or caretaker was unable to manage CIC (17), a minority of surgeons perform vesicostomy at first glance in the setting of elevated BUN to protect the kidney and prevent the progression of overwhelming sepsis (16). Others believe that the dilated urinary tract will not collapse even with maintained catheter drainage, so theyencourage peritoneal dialysis catheter insertion under vision to avoid iatrogenic GI and urinary injury (18). Other procedures occasionally performed including gastrostomy, jejunostomy and cecostomy in specific indications. Unfortunately, surgical interventions failed to improve enteral food intake, intestinal pseudoobstruction or bladder function ${ }^{4}$. Hence, several authors now agree that the decision for surgical interventions should be made on individual basis and mostly restricted to supportive interventions such vesicostomy and enterostomy (2).
Recently, multivisceral transplantation became a valuable therapeutic treatment for children with irreversible intestinal and/or total parenteral nutrition failure (19).

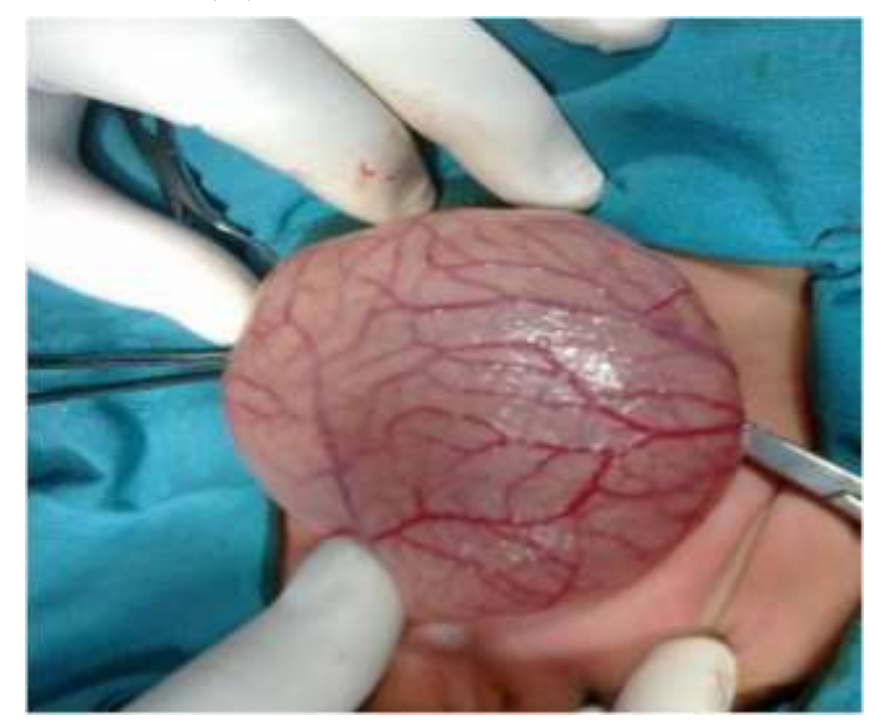

Figure (1). An Intra-operative picture showing the hugely distended bladder.

\section{Outcome}

Fifty one out of 236 patients were alive at the time of publication, which revealed an overall survival rate of $21.6 \%$ in this review. In a previous review (1976-2011), 43 out of 218 patients were alive at the time of publication (survival rate 19.7\%) ${ }^{4}$. In contrast, analysis of the more recent time period from 2011 to 2018 revealed an increase of the survival rate to $44 \%$ ( 8 out of 18 patients were alive at the time of publication). However, more cases are required in order to conclude a statistical significance. Unfortunately, no sufficient reports were performed to indicate long-term survival. The most frequently reported cause of death in MMIHS patients was overwhelming sepsis followed by multiple organ failure and malnutrition. There are several reasons for the development of sepsis in MMIHS patients. Firstly, intestinal conditions, such as malrotation and short bowel with the resulting functional obstruction of the bowel may cause bacterial overgrowth and translocation, hence, leads to bacteremia and subsequent sepsis. Moreover, urinary tract infections (UTI) as well as catheter-induced sepsis resulting from prolonged TPN can augment the sepsis (20). Lastly, in several cases, attempts to provide sufficient enteral feeding have resulted in fatal pneumonia (21).

Renal failure occurs as a consequence of aperistaltic urinary bladder with resultant reflux and repeated UTI leading to renal scarring. Liver dysfunction is a common complication. In a large survey conducted in Japan, it was reported in $84 \%$ of the cases, with 6 patients out of 9 died from liver failure. This failure was mostly attributed to the prolonged parentral nutrition with its devastating effect on liver, and less commonly due to enteritis and sepsis (22).

Only 12 transplantations were performed to date with a reported 3-year survival of $50 \%$ of those series. All survivors tolerated enteral feedings; however, bladder function did not improve and catheterisation had to be continued after transplantation (19). While there was a significant improvement of the results of multivisceral transplantation in the recent years (23), complications are inevitable. These include infection, rejection, and post-transplant lymphoproliferative disease (PTLD). Moreover, reports regarding long term complications and survival of MMIHS patients after transplantation are still lacking (24).

\section{Conclusion}

Although, recently, there was improvement in the survival rate of MMIHS compared to the past, yet, the mortality is still high. With the improvement in supportive care over time the life span of children with MMIHS may increase; however, intestinal transplantation appears to be the only viable therapy to restore gastrointestinal motility. 


\section{Conflict of interest}

The authors have no conflicts of interests.

\section{Funding}

This research did not receive any specific grant from funding agencies in the public, commercial, or not-for-profit sectors.

\section{Acknowledgements}

We thank Prof. Sameh Shehata, Professor of Pediatric Surgery, Alexandria Faculty of Medicine for his continuous and endless support, and tips in the process of publication.

\section{References}

1. Granata C, Puri P. Megacystis-microcolon-intestinal hypoperistalsis syndrome. J Pediatr Gastroenterol Nutr 1997;25:12-19.

2. Puri P, Shinkai M. Megacystis microcolon intestinal hypoperistalsis syndrome. Semin Pediatr Surg 2005;14:58-63

3. Raofi V, Beatty E, Testa G, Abcarian H, Oberholzer J, Sankary $\mathrm{H}$, et al. Combined living-related segmental liver and bowel transplantation for megacystis- microcolon- intestinal hypoperistalsis syndrome. J Pediatr Surg 2008;43:e9-e11.

4. Gosemann J, Puri P. Megacystis microcolon intestinal hypoperistalsis syndrome: systematic review of outcome. Pediatr Surg Int 2011;27:1041-1046.

5. Berdon WE, Baker DH, Blanc WA, Gay B, Santulli TV, Donovan C. Megacystis-microcolon-intestinal hypoperistalsis syndrome: a new cause of intestinal obstruction in the newborn. Report of radiologic findings in five newborn girls.Am $\mathbf{J}$ Roentgenol 1976;126:957-964.

6. Carter BA, Karpen SJ. Intestinal failure-associated liver disease: management and treatment strategies past, present,and future. Semin Liver Dis 2007;27:251-258.

7. Young ID, McKeever PA, Brown LA, Lang GD. Prenatal diagnosis of the megacystis-microcolon-intestinal hypoperistalsis syndrome. J Med Genet 1989;26:403-406.

8. Oliveira G, Boechat MI, Ferreira MA. Megacystis-microcolonintestinal hypoperistalsis syndrome in a newborn girl whose brother had prune belly syndrome: common pathogenesis? Pediatr Radiol 1983;13:294-296

9. Akhtar T, Alladi A, Siddappa OS (2012). Megacystismicrocolon-intestinal hypoperistalsis syndrome associated with prune belly syndrome: a case report. J Neonat Surg; 1: 26.

10. Maruyama H, Hasegawa Y, Sugibayashi R, Iwasaki Y, Fujino S, Amari S, et al (2018). Megacystis microcolon intestinal hypoperistalsis syndromeoverlapping prune belly syndrome. J Pediatr Surg Case Rep; 34:54-57.

11. Mc Laughlin D, Puri P(2013). Familial megacystis microcolon intestinal hypoperistalsis syndrome: a systematic review.Pediatr Surg Int; 29:947-951.
12. Halim D, Wilson MP, Oliver D, Brosensa E, Verheijd J, Yu Han $\mathrm{Y}$, et al(2017). Loss of LMOD1 impairs smooth muscle cytocontractility and causes megacystis microcolon intestinal hypoperistalsis syndrome in humans and mice. Proc Natl Acad Sci U S A; 114:e2739-e2747.

13. Tuzovic L, Anyane-Yeboa K, Mills A, Glassberg K, Miller R (2014). Megacystis-microcolon-intestinal hypoperistalsissyndrome: case report and review of prenatal ultrasonographicfindings. Fetal Diagn Ther; 36: 74-80.

14. Machado L, Matias A, Rodrigues M, Mariz C, Monteiro J, Montenegro N(2013). Fetal megacystis as a prenatal challenge: megacystis-microcolon-intestinal hypoperistalsis syndrome in a male fetus. Ultrasound Obstet. Gynecol.;41:345-347.

15. 15. Garel C, Dreux S, Philippe-Chomette P, Vuillard E, Oury JF, Muller F(2006). Contribution of fetal magnetic resonance imaging and amniotic fluid digestive enzyme assays to the evaluation of gastrointestinal tract abnormalities. UltrasoundObstet Gynecol;28:282e91.

16. Elrouby A, Kotb M, Abdelatty M, Waheeb S (2019). MegacystisMicrocolon-intestinal hypoperistalsis syndrome. J Pediatr Surg Case Rep; 41:4-7.

17. Wymer KM, Anderson BB, Wilkens AA, Gundeti MS (2016). Megacystis microcolon intestinal hypoperistalsis syndrome: Case series and updated review of the literature with an emphasis on urologic management. J Pediatr Surg;51:1565-1573.

18. Hiradfar M, Shojaeian R, Dehghanian P, Hajianet S (2013). Megacystis microcolon intestinal hypoperistalsis syndrome. BMJ Case Rep. Doi: 10.1136/bcr-2012-007524

19. Loinaz C, Rodriguez MM, Kato T, Mittal N, Romaguera RL, Bruce $\mathrm{JH}$, et al(2005). Intestinal and multivisceral transplantation in children with severe gastrointestinal dysmotility. J Pediatr Surg;40:1598-1604

20. Melek M, Edirne Y, Beger B, Cetin M (2009).

Megacystismicrocolon- intestinal hypoperistalsis syndrome: a case report. Gastroenterol Res Pract: 282-753.

21. Nazer H, Rejjal A, Abu-Osba Y, Rabeeah A, Ahmed S(1995). Megacystis-microcolon-intestinal hypoperistalsis syndrome. Saudi J Gastroenterol;1:180-183.

22. Soh H, Fukuzawa M, Kubota A, Kawahara H, Ueno T, Taguchi $\mathrm{T}(2015)$. Megacystis microcolon intestinal hypoperistalsis syndrome: a report of a nationwide survey in Japan. J Pediatr Surg; 50:2048-2050.

23. Farmer DG, Venick RS, Colangelo J, Esmailian Y, Yersiz H, Duffy JP, et al(2010). Pretransplant predictors of survival after intestinal transplantation: analysis of a single-center experience of more than 100 transplants. Transplantation; 90:1574-1580.1

24. Phillips GS, Bhargava P, Stanescu L, Dick AA, Parnell SE (2011). Pediatric intestinal transplantation: normal radiographic appearance and complications. Pediatr Radiol; 41:1028-1039. 